\title{
Roles of Long Non-coding RNAs in the Development of Chronic Pain
}

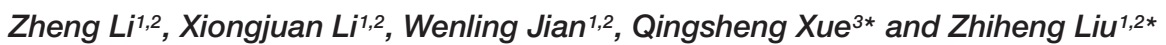 \\ 'Department of Anesthesiology, The First Affiliated Hospital of Shenzhen University, Shenzhen Second People's Hospital, \\ Shenzhen, China, ${ }^{2}$ Department of Geriatric \& Spinal Pain Multi-Department Treatment, The First Affiliated Hospital \\ of Shenzhen University, Shenzhen Second People's Hospital, Shenzhen, China, ${ }^{3}$ Department of Anesthesiology, Ruijin \\ Hospital, School of Medicine, Shanghai Jiao Tong University, Shanghai, China
}

\section{OPEN ACCESS}

Edited by:

Xiaodong Liu,

The Chinese University of Hong Kong,

Hong Kong SAR, China

Reviewed by:

Mian Peng,

Wuhan University, China

Chamini Perera,

University of New South Wales,

Australia

Yu-Qing Wu,

Xuzhou Medical University, China

*Correspondence:

Qingsheng Xue

xqs11260@rih.com.cn

Zhiheng Liu

zhiheng_liu_tongji@163.com

Specialty section:

This article was submitted to Pain Mechanisms and Modulators,

a section of the journal

Frontiers in Molecular Neuroscience

Received: 19 August 2021

Accepted: 21 October 2021

Published: 23 November 2021

Citation:

Li Z, Li X, Jian W, Xue Q and Liu Z (2021) Roles of Long Non-coding RNAs in the Development of Chronic

Pain.

Front. Mol. Neurosci. 14:760964. doi: 10.3389/fnmol.2021.760964
Chronic pain, a severe public health issue, affects the quality of life of patients and results in a major socioeconomic burden. Only limited drug treatments for chronic pain are available, and they have insufficient efficacy. Recent studies have found that the expression of long non-coding RNAs (IncRNAs) is dysregulated in various chronic pain models, including chronic neuropathic pain, chronic inflammatory pain, and chronic cancer-related pain. Studies have also explored the effect of these dysregulated IncRNAs on the activation of microRNAs, inflammatory cytokines, and so on. These mechanisms have been widely demonstrated to play a critical role in the development of chronic pain. The findings of these studies indicate the significant roles of dysregulated IncRNAs in chronic pain in the dorsal root ganglion and spinal cord, following peripheral or central nerve lesions. This review summarizes the mechanism underlying the abnormal expression of IncRNAs in the development of chronic pain induced by peripheral nerve injury, diabetic neuropathy, inflammatory response, trigeminal neuralgia, spinal cord injury, cancer metastasis, and other conditions. Understanding the effect of IncRNAs may provide a novel insight that targeting IncRNAs could be a potential candidate for therapeutic intervention in chronic pain.

Keywords: long non-coding RNA, chronic neuropathic pain, chronic cancer-related pain, dorsal root ganglion, spinal cord

Abbreviations: AQP4, Aquaporin 4; BCP, bone cancer pain; BDNF, brain-derived neurotrophic factor; CCRP, chronic cancer-related pain; CCI, chronic constriction injury; CDK, cyclin-dependent kinase; ceRNA, competitive endogenous RNA; CFA, Complete Freund's Adjuvant; CGRP, calcitonin gene-related peptide; CIP, cancer-induced pain; CIPN, chemotherapyinduced peripheral neuropathy; CNP, chronic neuropathic pain; CRNDE, colorectal neoplasia differentially expressed; CRPS, complex regional pain syndrome; CXCL13, chemokine ligand 13; CXCL9, chemokine ligand 9; CXCR5, chemokine receptor 5; DGCR5, DiGeorge syndrome critical region gene 5; DILC, downregulated in liver cancer stem cells; DLEU1, deleted in lymphocytic leukemia 1; DNP, diabetic neuropathic pain; DRG, dorsal root ganglion; ELAVL1, embryonic lethal abnormal version-like RNA-binding protein 1; ERK 1/2, extracellular regulated protein kinases 1/2; exo-lncRNA H19, exosome containing lncRNA H19; FIRRE, functional intergenic repeating RNA element; GAS5, growth-arrest-specific 5; GO, Gene ontology; HMGB1, high-mobility group box 1; IL-1 $\beta$, Interleukin-1 $\beta$; IL-6, Interleukin-6; IL-12, Interleukin-12; JAK, Janus kinase; KCNA2-AS, KCNA antisense RNA; KEGG, Kyoto Encyclopedia of Genes and Genomes; lncRNAs, long non-coding RNAs; MALAT1, Metastasis-associated lung adenocarcinoma transcript (MALAT)1; MAPK, mitogen-activated protein kinases; MEG3, maternally expressed gene 3; miR, miRNA; NEAT1, nuclear paraspeckle assembly transcript 1; NF- $\mathrm{kB}$, nuclear factor-kappaB; $\mathrm{NO}$, nitric oxide; $\mathrm{OA}$, osteoarthritis; $\mathrm{P} 2 \mathrm{X}_{3} \mathrm{R}, \mathrm{P} 2 \mathrm{X}_{3}$ receptor; $\mathrm{P} 2 \mathrm{X}_{7} \mathrm{R}, \mathrm{P} 2 \mathrm{X}_{7}$ receptor; PNI, peripheral nerve injury; PVT1, plasmacytoma variant translocation 1; SC, spinal cord; SCI, spinal cord injury; SGCs, satellite glial cells; siRNA, small interference RNA; SNHG1, small nucleolar RNA host gene 1; SNHG5, small nucleolar RNA host gene 5; SNI, spared sciatic nerve injury; SNL, spinal nerve ligation; STAT3, signal transducer and activator of transcription 3; TG, trigeminal ganglia; TN, trigeminal neuralgia; TNF- $\alpha$, tumor necrosis factor; TRPV1, transient receptor potential vanilloid type 1; UCBMSCs, umbilical cord blood mesenchymal stem cells; XIST, X-inactive specific transcript; YY1, Yin-Yang 1. 


\section{INTRODUCTION}

Chronic pain is an extremely prevalent healthcare issue that affects the quality of life of patients, resulting in an annual financial impact (van Hecke et al., 2014; Hamood et al., 2018). It can be generally categorized as chronic cancer-related pain or chronic non-cancer-related pain, such as chronic neuropathic pain (CNP) and chronic postsurgical or posttraumatic pain (Treede et al., 2019). Although many studies have elucidated the mechanisms underlying the development of chronic pain, only a few currently available clinical therapeutic strategies effectively alleviate pain symptoms in patients with limited unwanted side effects. Thus, it is imperative to explore novel targets for the treatment of chronic pain.

Long non-coding RNA, which consists of more than 200 nucleotides, is a non-coding RNA that lacks a complete open reading frame (Batista and Chang, 2013). Although they cannot translate into detectable proteins individually, long non-coding RNAs (lncRNAs) can play a crucial role in the expression and translation of other genes and whole gene networks by interacting with DNA, proteins, and other RNAs (Wang and Chang, 2011). Accumulating evidence indicates that lncRNAs are potent regulators of physiological and pathological processes, such as embryonic development, cancer, inflammation, and neurological diseases (Ulitsky and Bartel, 2013). Recently, many studies have identified changes in the expression and important role of lncRNAs in chronic pain models. Therefore, this review aimed to explore the roles and mechanisms of lncRNAs in the development of chronic pain, including $\mathrm{CNP}$ and chronic cancerrelated pain (CCRP).

\section{THE ROLE OF IncRNAs IN THE NERVOUS SYSTEM AND THE PAIN-SIGNALING PATHWAY}

Dysregulated lncRNA expression has been found in damaged nerves, primary sensory dorsal root ganglion neurons, spinal cord, and postsynaptic dorsal horn after peripheral nerve lesions or spinal cord injury (SCI). Under these conditions, accumulating evidence has shown the effect of the interaction between lncRNAs and miRNAs in the development of chronic pain. As a competitive endogenous RNA (ceRNA) (Chen et al., 2017; Sun et al., 2019), lncRNAs can competitively bind miRNAs, inhibit the interaction between miRNAs and downstream genes, and regulate the transcription and expression of downstream genes. For example, lncRNA MALAT1 can sponge miR-129-5p as a ceRNA and upregulate the expression of high-mobility group box 1 (HMGB1) in the spinal cord, promoting the development of CNP (Zhao et al., 2016). IncRNA CRNDE can upregulate the expression of IL-6 receptors in chronic pain by interacting with miR-136 (Zhang et al., 2019). In addition, lncRNA Linc01119 can interact with embryonic lethal abnormal version-like RNAbinding protein 1 (ELAVL1), upregulate the expression of brainderived neurotrophic factor (BDNF) at the mRNA and protein levels, and induce chronic pain in the spinal cord and DRG (Zhang L. et al., 2021). In summary, lncRNAs can interact with
miRNA or RNA-associated proteins and regulate the different downstream mechanisms involved in chronic pain.

In addition, some lncRNAs have been reported to mediate the activation of signaling pathways (Ren et al., 2020) and participate in the development of chronic pain. IncRNA LOC100911498 small interfering RNA (siRNA) treatment can decrease the phosphorylation of the p38 pathway in the spinal cord induced by chronic pain (Tang et al., 2021). Another study suggested that activation of the ERK1/2 pathway in the DRG is regulated by lncRNA uc.48+ (Wang et al., 2016). p38 and ERK1/2 can participate in the development of chronic pain (Lin et al., 2014; Qian et al., 2019). In addition, $\mathrm{P} 2 \mathrm{X}_{3}$ and $\mathrm{P} 2 \mathrm{X}_{7}$ receptors have been found to be regulated by lncRNAs (Seino et al., 2006; Peng H. et al., 2017). The two receptors play a role in the development of chronic pain (Wu et al., 2021; Xia et al., 2021). Furthermore, the levels of pro-inflammatory factors, such as IL- $1 \beta$, IL-6, IL12, and TNF- $\alpha$ (Xia et al., 2018; Li Z. et al., 2020; Pan et al., 2020), have been found to change in chronic pain after lncRNA downregulation. Neuroinflammation plays a significant role in chronic pain. Thus, the effect of lncRNAs on the development of chronic pain may involve various mechanisms (Figure 1).

\section{InCRNAs AND CHRONIC NEUROPATHIC PAIN}

Chronic neuropathic pain (CNP), a major public health concern worldwide, affects the quality of life of $6.9-10 \%$ of the general population (van Hecke et al., 2014). CNP is characterized by spontaneous ongoing or evoked by sensory stimuli (hyperalgesia and allodynia). It is mainly observed in peripheral nerve lesions [diabetic neuropathy, peripheral nerve injury (PNI), and trigeminal neuralgia (TN)] or central nerve lesions (SCI) (Scholz et al., 2019). Various animal models of peripheral neuropathic pain and central neuropathic pain have been established to explore the mechanisms underlying the development of CNP (Tian et al., 2020; Zhang P. et al., 2021). However, the treatment of CNP remains a major challenge. Recent accumulating evidence has shown that lncRNAs are related to the development of peripheral neuropathic pain and central neuropathic pain (Liu et al., 2018; Sun et al., 2018; Tian et al., 2020; Xu et al., 2020).

\section{IncRNAs and Peripheral Neuropathic Pain IncRNAs and Peripheral Nerve Injury}

Peripheral nerve injury, which induces CNP, is a common clinical cause of peripheral nerve lesions. PNI can cause excitability of the primary sensory ganglia or the spinal cord in the nervous system (Tsuda et al., 2009), which plays a role in pain-signaling transmission. Most animal models, such as those of chronic constriction injury (CCI), spinal nerve ligation (SNL), and spared sciatic nerve injury (SNI), have been used to investigate the relationship between lncRNAs and CNP in the nervous system (Table 1 and Figure 2). Zhao et al. (2013) were the first to show that the expression of a new native lncRNA was upregulated in mammalian DRG neurons of SNL and CCI model mice. Since the sequence of this IncRNA was found to be complementary 


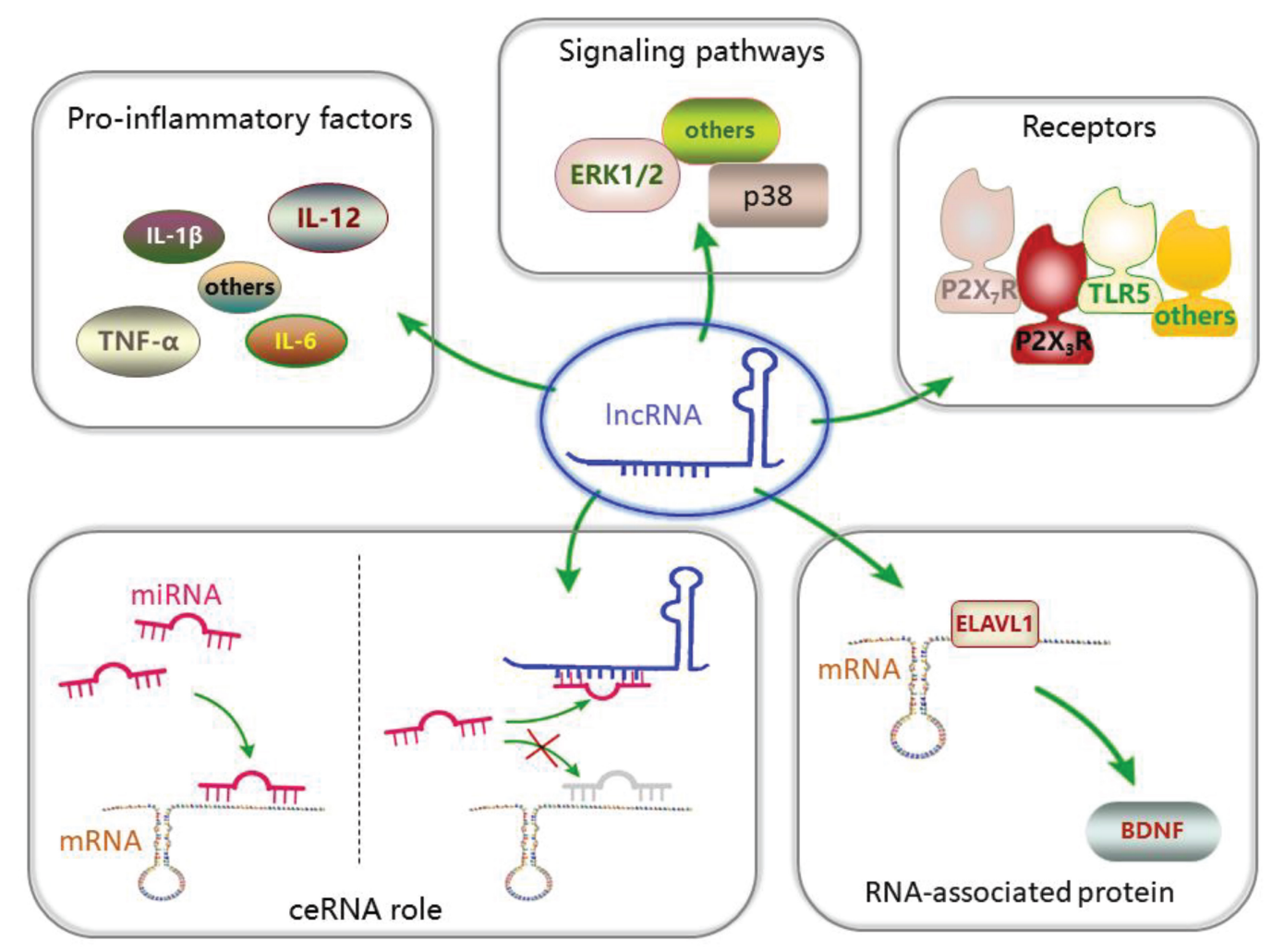

FIGURE 1 | Long non-coding RNA (IncRNAs) and their mechanism in pain transmission: IncRNAs can participate in pain transmission through various mechanisms.

to that of KCNA2 RNA, the researchers named it as KCNA antisense (KCNA2-AS). KCNA2-AS was identified to trigger the downregulation of KCNA2 in the DRG and participate in the development of neuropathic pain by using KCNA2-AS siRNA, indicating the important role of lncRNAs in CNP development. The following studies were performed to explore the roles and mechanisms of lncRNAs in the development of PNI-induced CNP. IncRNAs, such as MALAT1, DILC, FIRRE, XIST, H19, and DGCR 5 in the spinal cord, have been found to have a continuous effect on CNP (Wei et al., 2018; Peng et al., 2019; Li K. et al., 2020; Liu et al., 2020; Wu et al., 2020; Wen et al., 2021). IncRNAs, such as H19, SNHG5, and MRAK009713 in DRG, have also been identified to play important roles in the development of CNP ( $\mathrm{Li}$ et al., 2017; Chen et al., 2020; Wen et al., 2020). Since numerous lncRNAs are involved, we have summarized the following points:

(1) Most lncRNAs interacted with miRNAs, and MALAT1 and XIST were the most common among these lncRNAs. miRNA downregulation triggered by these lncRNAs could influence the downstream mechanism and induce mechanical and cold hypersensitivity and the symptoms of PNI-associated CNP. In addition, other mechanisms of lncRNAs have been investigated in PNI models. DILC, Linc00311, AK141205, and KCNA2-AS have been reported to participate in CNP by regulating the JAK/STAT3-signaling pathway (Mao et al., 2018; Kong et al., 2020; Liu et al., 2020).
MRAK009713-mediated CNP development is involved in $\mathrm{P}_{2} \mathrm{X}_{3}$ receptor activation (Li et al., 2017). Cyclindependent kinases 4 and 6 (CDK4 and CDK6) have been found to be regulated by lncRNA SNHG1 and PKIA-AS1, respectively (Hu et al., 2019; Zhang J.Y. et al., 2020). Notably, changes in the levels of pro-inflammatory cytokines (IL-1 $\beta$, IL-6, and TNF- $\alpha$ ) have been found in most PNI models (Li Z. et al., 2020; Pan et al., 2020), indicating that lncRNA-mediated CNP development may be involved in neuroinflammation.

(2) The same issue could express various lncRNAs, which may be different expression levels or play opposite effect on the PNI model. In the spinal cord of CCI rats, DLEU1 expression was upregulated (Li Z. et al., 2020), whereas GAS5 expression was downregulated (Tian et al., 2020). Thus, the two lncRNAs played opposite roles in the development of PNI-induced CNP. In addition, the expression of the same lncRNA in different conditions or models may display opposite changes. MALAT1 expression was increased in the L4-L6 spinal cord of male CCI rats (Ma et al., 2020), while its expression was reduced in the C5-T1 spinal cord of male complete brachial plexus avulsion rats (Meng et al., 2019).

(3) Owing to the sex difference in pain sensitivity (Fullerton et al., 2018), clinical and experimental findings have suggested that women are more sensitive to pain than men (Fillingim et al., 2009). lncRNA XIST, which mediates 
TABLE 1 | IncRNAs and peripheral nerve injury.

\begin{tabular}{|c|c|c|c|c|c|}
\hline Model & IncRNAs & Distribution & Expression & Mechanism & References \\
\hline \multirow[t]{21}{*}{$\mathrm{CCl}$} & \multirow[t]{3}{*}{ MALAT1 } & SC of female rat & $\uparrow$ & MALAT1/miR-154-5p/AQP9 axis & Wu et al., 2020 \\
\hline & & SC of female rat & $\uparrow$ & MALAT1/miR-206/ZEB2 axis & Chen Z.L. et al., 2019 \\
\hline & & $\mathrm{SC}$ of male rat & $\uparrow$ & MALAT1/miR-129-5p/HMGB1 axis & Ma et al., 2020 \\
\hline & DILC & $\mathrm{SC}$ of male rat & $\uparrow$ & SOCS3/JAK2/STAT3 pathway & Liu et al., 2020 \\
\hline & FIRRE & $\mathrm{SC}$ of female mouse & $\uparrow$ & HMGB1 & Wen et al., 2021 \\
\hline & CRNDE & $\mathrm{SC}$ of rat & $\uparrow$ & $\begin{array}{l}\text { CRNDE/miR-136/IL6R axis, IL-1, IL-6, } \\
\text { IL-10, TNF- } \alpha\end{array}$ & Zhang et al., 2019 \\
\hline & \multirow[t]{4}{*}{ XIST } & SC of female rat & $\uparrow$ & $\mathrm{XIST} / \mathrm{miR}-154-5 \mathrm{p} / \mathrm{TLR} 5$ axis & Wei et al., 2018 \\
\hline & & $\mathrm{SC}$ of female rat & $\uparrow$ & $\mathrm{XIST} / \mathrm{miR}-150 / Z \mathrm{~EB} 1$ axis & Yan et al., 2018 \\
\hline & & SC of female rat & $\uparrow$ & $\begin{array}{l}\text { XIST/miR-544/STAT3 axis, TNF- } \alpha, \text { IL-1 } \beta \text {, } \\
\text { IL-6 }\end{array}$ & Jin et al., 2018 \\
\hline & & SC of female rat & $\uparrow$ & XIST/miR-137/TNFAIP1 axis & Zhao et al., 2018 \\
\hline & Linc00657 & SC of female rat & $\uparrow$ & Linc00657/miR-136/ZEB1 axis & Shen et al., 2019 \\
\hline & NEAT1 & SC of female rat & $\uparrow$ & $\begin{array}{l}\text { NEAT1/miR-381/HMGB1 axis, IL-6, } \\
\text { IL-1 } 1 \beta, \text { TNF- } \alpha\end{array}$ & Xia et al., 2018 \\
\hline & uc. 153 & $\mathrm{SC}$ of male mouse & $\uparrow$ & $\begin{array}{l}\text { uc.153/miR-182-5p/EphB1-NMDA } \\
\text { receptors }\end{array}$ & Zhang C. et al., 2020 \\
\hline & Linc00311, AK141205 & $\mathrm{SC}$ of male rat & $\uparrow$ & STAT3, IL-6, IL-1 $\beta$ & Pang et al., 2020 \\
\hline & SNHG16 & SC of female rat & $\uparrow$ & $\begin{array}{l}\text { SNHG16/miR-124-3p, } \\
\text { miR-141-3p/JAG1 axis, IL- } 6 \text {, TNF- } \alpha \text {, } \\
\text { IL-1 } \beta\end{array}$ & Li H. et al., 2020 \\
\hline & GAS5 & SC of female rat & $\downarrow$ & GAS5/miR-452-5p/CELF2 axis & Tian et al., 2020 \\
\hline & DLEU1 & SC of female rat & $\uparrow$ & $\begin{array}{l}\text { DLEU1/miR-133a-3p/SRPK1 axis, IL-6, } \\
\text { TNF- } \alpha, \text { IL-1 } \beta\end{array}$ & Li Z. et al., 2020 \\
\hline & $\mathrm{H} 19$ & SC of rat & $\uparrow$ & H19/miR-196a-5p/CDK5 axis, p-CREB & Li K. et al., 2020 \\
\hline & HAGLR & SC of female rat & $\uparrow$ & HAGLR/miR-182-5p/ATAT1 axis, NLRP3 & Zhang Q. et al., 2021 \\
\hline & CCAT1 & $\begin{array}{l}\text { Hippocampus, SC, DRG } \\
\text { of male rat }\end{array}$ & $\downarrow$ & miR155, SGK3 & Dou et al., 2017 \\
\hline & MRAK009713 & DRG of male rat & $\uparrow$ & $\mathrm{P} 2 \mathrm{X}_{3}$ receptor & Li et al., 2017 \\
\hline $\mathrm{SNL}, \mathrm{CCl}$ & Kcna2-AS & DRG neuron of male rat & $\uparrow$ & MZF1/Kcna2-AS/Kcna2 & Zhao et al., 2013 \\
\hline \multirow[t]{8}{*}{ SNL } & PKIA-AS1 & $\mathrm{SC}$ of male rat & $\uparrow$ & CDK6 & Hu et al., 2019 \\
\hline & SNHG1 & $\mathrm{SC}$ of male rat & $\uparrow$ & CDK4 & Zhang J.Y. et al., 2020 \\
\hline & SNHG4 & SC of male rat & $\uparrow$ & miR-423-5p, IL-6, IL-12, TNF- $\alpha$ & Pan et al., 2020 \\
\hline & SNHG5 & L5 DRG of male mouse & $\uparrow$ & SNHG5/miR-154-5p/CXCL13 axis & Chen et al., 2020 \\
\hline & P21 & SC of male rat & $\uparrow$ & P21/miR-181b/Tnfaip1, AKT/CREB axis & Liu et al., 2021 \\
\hline & Linc00052 & $\mathrm{SC}$ of male rat & $\uparrow$ & $\begin{array}{l}\text { Linc00052/miR-448/JAK1 axis, IL-6, } \\
\text { TNF- } \alpha\end{array}$ & Wang L. et al., 2020 \\
\hline & $\mathrm{H} 19$ & DRG of male mouse & $\uparrow$ & Unknown & Wen et al., 2020 \\
\hline & Lncenc1 & DRG of male mouse & $\uparrow$ & $\begin{array}{l}\text { Lncenc1/EZH2/BAl1 } \\
\text { TNF- } \alpha, I L-1 \beta, I L-10\end{array}$ & Zhang Z. et al., 2021 \\
\hline \multirow[t]{5}{*}{$\mathrm{SNI}$} & AC111653.1 & DRG of male rat & $\uparrow$ & Unknown & Mao et al., 2018 \\
\hline & DGCR5 & SC of female rat & $\downarrow$ & DGCR5/miR-330-3p/PDCD4 axis & Peng et al., 2019 \\
\hline & LOC100911498 & L4, L5 SC of male rat & $\uparrow$ & $\mathrm{P} 2 \mathrm{X}_{4} \mathrm{R}, \mathrm{BDNF}, \mathrm{p} 38$ & Tang et al., 2021 \\
\hline & Slc6a19os, Sox11 & $\begin{array}{l}\text { L3-L5 DRG of male } \\
\text { mouse }\end{array}$ & $\uparrow$ & $\begin{array}{l}\text { miR-125a-5p, miR-125b-5p, } \\
\text { miR-351-5p }\end{array}$ & Chen et al., 2021 \\
\hline & Linc01119 & $\begin{array}{l}\text { L4-L5 SC and DRGs of } \\
\text { male rats }\end{array}$ & $\uparrow$ & Linc01119/ELAVL1/BDNF axis & Zhang L. et al., 2021 \\
\hline $\begin{array}{l}\text { Complete brachial } \\
\text { plexus avulsion }\end{array}$ & MALAT1 & $\begin{array}{l}\text { cytoplasm of neurons in } \\
\text { male rat C5-T1 SC }\end{array}$ & $\downarrow$ & Unknown & Meng et al., 2019 \\
\hline PHN & Kcna2-AS & L4, L5 SC of female rat & $\uparrow$ & STAT3, astrocyte & Kong et al., 2020 \\
\hline
\end{tabular}

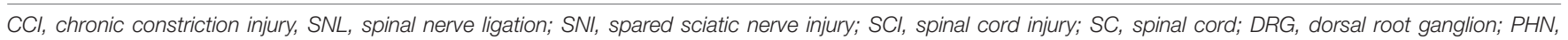
postherpetic neuralgia; $\uparrow$, upregulated expression; $\downarrow$, downregulated expression.

$\mathrm{X}$-chromosome inactivation or reactivation in female cells (Vacca et al., 2016), has been found to play an important role in female PNI models (Jin et al., 2018; Wei et al., 2018;
Yan et al., 2018; Zhao et al., 2018). However, most lncRNAs exert their effect on all PNI models, regardless of sex, indicating that most lncRNAs can play an important role 
in the development of PNI-induced CNP in both female and male models.

(4) Many studies have paid attention to the effect of lncRNAs on spinal cord and DRG. However, various specific brain regions, such as hippocampus, periaqueductal gray (PAG), anterior cingulate cortex (ACC), can also exert their effect on the development of chronic pain (Bliss et al., 2016; Ong et al., 2019). Dou et al. (2017) found the decrease of the lncRNA CCAT1 level in hippocampus and ACC of the CCI model. Overexpression of CCAT1 could alleviate CNP and inhibit the increased miR-155. As a role of ceRNA, CCAT1 could inhibit miRNA expression, and the researcher further identified the role of serum and glucocorticoid-regulated protein kinase 3 (SGK3) in CCAT1-mediated miR-155 expression and CCAT1induced CNP. These results indicated the significant role of lncRNA in hippocampus and ACC. However, the effect of lncRNAs on specific brain regions needs to be explored in the future.

\section{IncRNAs and Diabetic Neuropathic Pain}

Diabetic neuropathic pain (DNP), a painful diabetic peripheral neuropathy, is one of the most common types of neuropathic pain (de Vos et al., 2014), and it commonly manifests as allodynia, hyperalgesia, or spontaneous pain (Wang et al., 2014). Approximately, $40-50 \%$ of patients with diabetes experience DNP (Schreiber et al., 2015), whereas effective therapies for DNP remain elusive. Recently, genome-wide expression patterns of lncRNAs have been identified, and RT-qPCR validated the dysregulation of lncRNAs in the spinal cord of DNP mice (Du et al., 2019). Bioinformatics analysis results have shown that these lncRNA-related genes are involved in calcium ion transport, which participates in neuropathic pain development (Baba et al., 2016). However, the speculation that lncRNA exerts an effect on the ion channel in DNP needs to be further explored (Table 2).

Liu et al. (2018) identified the role of lncRNAs in DNP by regulating transient receptor potential vanilloid type 1 (TRPV1) activation in the rat DRG. Using western blot analysis, they found that high TRPV1 receptor expression in DRG neurons of DNP rats could be substantially decreased by IncRNA BC168687 siRNA, which could alleviate TRPV1mediated diabetic neuropathic pain (Zhang B.Y. et al., 2020), indicating that lncRNA BC168687 may regulate the ion channel of DRG neurons and participate in the development of DNP. In addition, Liu et al. (2018) found that $\mathrm{P}_{2} \mathrm{X}_{7}$ receptor expression was downregulated after BC168687 siRNA treatment. The P2X receptor is mainly expressed in satellite glial cells (SGCs) (Chen et al., 2012; Puchałowicz et al., 2015), which tightly enwrap the DRG (Costa and Moreira Neto, 2015). Previous studies have suggested that SGC $\mathrm{P}_{2} \mathrm{X}_{7}$ receptors play an important role in neuropathic pain (Kuan and Shyu, 2016; Bernier et al., 2018). Liu et al. (2017) found that treatment with BC168687 siRNA decreased the serum level of oxidative injury factors (e.g., NO) released by SGCs in a DNP model. NO can strengthen the sensitivity of neurons to noxious stimulation in the DRG (Thippeswamy et al., 2005). NO has been reported to be involved in the development of neuropathic pain (Rondón et al., 2018). Thus, BC168687 may promote interaction with neurons and glia in the DRG during DNP. These data indicate that lncRNA BC168687 in DRG may participate in the development of DNP by regulating the activation of both neurons and glia.

Long non-coding RNA NONRATT021972 has also been validated to play an important role in the development of DNP (Liu et al., 2016). Using lncRNA siRNA, P2X 7 antagonist, and electrophysiological recordings of neurons, this lncRNA was found to regulate $\mathrm{P}_{2} \mathrm{X}_{7}$ receptor expression in the SGCs of the DRG during DNP. Peng H. et al. (2017) explored the direct effect of this lncRNA on DRG neurons. NONRATT021972 siRNA inhibited the expression and activation of the $\mathrm{P}_{2} \mathrm{X}_{3}$ receptor and its downstream ERK1/2-signaling pathway in neurons and relieved DNP. The ERK1/2-signaling pathway is involved in neuropathic pain transmission (Seino et al., 2006). These results indicate that IncRNA NONRATT021972 in the DRG may participate in the development of DNP by regulating the activation of both neurons and glia.

Similarly, the $\mathrm{P}_{2} \mathrm{X}_{3}$ receptor and ERK1/2-signaling pathway in the DRG are regulated by another lncRNA uc.48+ (Wang et al., 2016). In addition, lncRNA uc.48+ siRNA can significantly suppress the expression of calcitonin gene-related peptide (CGRP), IL-1 $\beta$, and TNF- $\alpha$ in the spinal cord (Xiong et al., 2017). The expression of CGRP, IL-1 $\beta$, and TNF- $\alpha$ in the spinal cord may contribute to pain responses (Brown et al., 2008; Hansen et al., 2016). Thus, IncRNA uc.48+ may participate in the development of DNP by regulating the expression of the three factors in the spinal cord. The findings from the aforementioned studies suggest a role for lncRNA uc.48+ in the progression of DNP and provide various lines of evidence to explain the lncRNA-mediated mechanisms underlying the development of DNP.

\section{IncRNAs and Trigeminal Neuralgia}

Trigeminal neuralgia is a common type of neuropathic pain, and many treatments for $\mathrm{TN}$, including medical therapy and microvascular decompression, have been found to be ineffective (Bick and Eskandar, 2017). Recently, IncRNA Gm14461 expression has been found to be increased in the trigeminal ganglia (TG) of TN mice (Xu et al., 2020). The Gm14461 knockdown increased the mechanical withdrawal threshold of TN mice, indicating that Gm14461 may play a regulatory role in mechanical hyperalgesia in $\mathrm{TN}$ mice. Western blot analysis results suggested that the Gm14461 knockdown could downregulate the expression of CGRP and $\mathrm{P}_{2} \mathrm{X}_{3 / 7}$ receptors at the protein level in $\mathrm{TN}$ mice. The three proteins are reported to participate in the development of neuropathic pain (Hansen et al., 2016; Wu et al., 2021; Xia et al., 2021). Moreover, Gm14461 upregulates the expression of TNF- $\alpha$, IL-1 $\beta$, and IL- 6 (Xu et al., 2020). Another lncRNA uc.48+ interacts with the $\mathrm{P}_{2} \mathrm{X}_{7}$ receptor and promotes the expression of the $\mathrm{P} 2 \mathrm{X}_{7}$ receptor in TG (Xiong et al., 2019). Western blot analysis results suggests that the ERK-signaling pathway may be involved in this interaction between uc.48+ and $\mathrm{P}_{2} \mathrm{X}_{7}$ receptor. These findings suggest that lncRNAs may play an important role in the development of TN through various mechanisms. 


\section{SC of male animal}

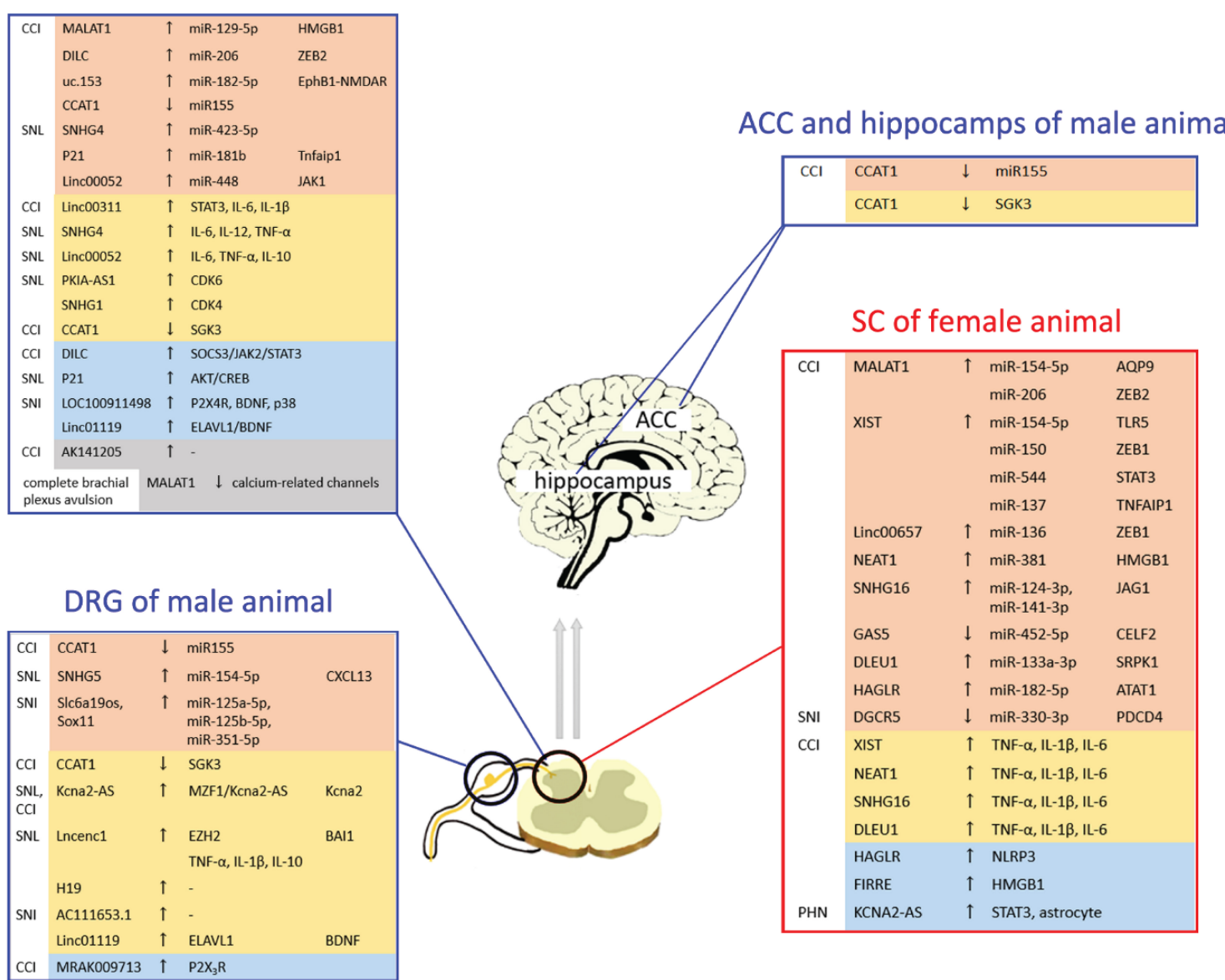

FIGURE 2 | Distribution of deregulated long non-coding RNAs (IncRNAs) with the respective associated mechanisms in peripheral nerve injury (PNI): IncRNAs can participate in the development of PNI-induced chronic neuropathic pain (CNP) through various mechanisms. The same IncRNA displays different expressions in different models or issues. Most IncRNAs can play an important role in the development of PNI-induced CNP in both female and male models. ACC, anterior cingulate cortex; DRG, dorsal root ganglion; SC, spinal cord.

\section{IncRNAs and Central Neuropathic Pain Associated With Spinal Cord Injury}

Chronic neuropathic pain is one of the most common complications of SCI that severely influences the quality of life of patients with SCI (Bouhassira et al., 2008). A bioinformatics analysis was performed to determine the dysregulation of lncRNA expression associated with pain transmission in blood samples from patients with SCI (Zhao et al., 2021). Two lncRNAs (Linc01119 and Linc02447) involved in the pain pathway indicated that lncRNA-mediated pain transmission may play a role in the development of SCI-induced CNP. Xian et al. (2021) confirmed the role of lncRNAs in the spinal cord of the CNP model. IncRNA NEAT1 expression was increased in the spinal cord of SCI rats, and NEAT1 inhibition alleviated SCI-induced CNP. miR-128-3p was downregulated by NEAT1 overexpression, as it played the role of its ceRNA, and the levels of AQP4, IL-6, IL-1 $\beta$, and TNF $\alpha$ were increased after miR-128-3p inhibition. Another study suggested that upregulated lncRNA PVT1 could alleviate SCI-induced CNP by targeting the miR-186-5p/CXCL13/CXCR5 axis (Zhang P. et al., 2021). CXCL13, CXCR5, and AQP4 are vital regulators of the inflammatory response in the nervous system (Liang et al., 2016; Bu et al., 2019). Thus, these two studies indicated the role and the mechanism of lncRNAs in the development of SCI-induced CNP, including their interaction with miRNAs or indirect regulation of the inflammatory response.

\section{IncRNAs AND COMPLEX REGIONAL PAIN SYNDROME-INDUCED INFLAMMATORY PAIN}

Complex regional pain syndrome (CRPS) is a chronic pain disorder characterized by intense pain, inflammation, and altered autonomic function (de Mos et al., 2007). The mechanism underlying the development of CRPS remains unclear (Birklein and Schlereth, 2015). Since women are about four times more likely than men to develop CRPS (Schwartzman et al., 2009), 
TABLE 2 | IncRNAs and diabetic neuropathic pain.

\begin{tabular}{|c|c|c|c|c|c|}
\hline Model & IncRNAs & Distribution & Expression & Mechanism & References \\
\hline \multirow[t]{7}{*}{ DNP } & BC168687 & DRG of male rat & $\uparrow$ & TRPV1, ERK1/2, p38, TNF- $\alpha, \| L-1 \beta$ & Liu et al., 2018 \\
\hline & & DRG of male rat & $\uparrow$ & $\mathrm{P} 2 \mathrm{X}_{7} \mathrm{R}, \mathrm{NO}$ & Liu et al., 2017 \\
\hline & NONRATT021972 & DRG of rat & $\uparrow$ & $\mathrm{P} 2 \mathrm{X}_{7} \mathrm{R}, \mathrm{TNF}-\alpha$, astrocyte & Liu et al., 2016 \\
\hline & & DRG of male rat & $\uparrow$ & $\mathrm{P} 2 \mathrm{X}_{3} \mathrm{R}, \mathrm{ERK} 1 / 2$ & Peng H. et al., 2017 \\
\hline & & Blood sample of male rat & $\uparrow$ & $\mathrm{TNF}-\alpha$ & Yu et al., 2017 \\
\hline & uc.48+ & DRG of male rat & $\uparrow$ & $\mathrm{P} 2 \mathrm{X}_{3} \mathrm{R}, \mathrm{ERK} 1 / 2$ & Wang et al., 2016 \\
\hline & & SC of male rat & $\uparrow$ & CGRP, ERK1/2, p38 & Xiong et al., 2017 \\
\hline
\end{tabular}

DNP, diabetic neuropathic pain; $\uparrow$, upregulated expression.

Shenoda et al. (2018) investigated the role of lncRNA XIST in the development of CRPS. XIST promotes and maintains X-chromosome inactivation (Wang et al., 2021), which refers to the random selection and transcriptional silencing of one of the two X-chromosomes in females, indicating the association of its effect with sex differences. RT-qPCR analysis results suggested that the expression of XIST was increased, and the upstream expression of miR-34a was decreased in the blood samples of patients with CRPS (Shenoda et al., 2018). As a role of a ceRNA, XIST in blood was identified to be directly regulated by miR-34a in a complete Freund's adjuvant (CFA)-induced inflammatory pain model. The pro-inflammatory transcription factor, Yin-Yang 1 (YY1), was found to participate in miR-34a-mediated XIST expression. Thus, miRNA-mediated downregulation of XIST expression in the blood may be a potential strategy for relieving CRPS-induced inflammatory pain. Another study found that XIST expression in the DRG was increased in a CFA-induced inflammatory pain model, and the XIST knockdown inhibited activated the Nav1.7 channel and levels of IL- 6 and TNF- $\alpha$ in the DRG and attenuated inflammatory pain (Sun et al., 2018). These studies indicate that XIST is regulated by miRNAs and mediates the release of pro-inflammatory factors, participating in the development of inflammatory pain, demonstrating a new mechanism underlying inflammatory pain. However, the mechanism underlying CRPSinduced inflammatory pain in male patients needs to be further explored.

\section{IncRNAs AND \\ OSTEOARTHRITIS-INDUCED INFLAMMATORY PAIN}

Osteoarthritis is one of the most common forms of arthritis (Sellam and Berenbaum, 2010). Its clinical manifestations include joint swelling, synovitis, and inflammatory pain, which cause pain to the patient. Many studies have indicated the regulatory role of lncRNAs in the inflammatory process of OA. Many lncRNAs can attenuate OA through the interaction between lncRNAs and miRNAs (Xie et al., 2020), MAPK pathway (Xiao et al., 2019), and pro-inflammatory factors (Li et al., 2018a). However, the role of lncRNAs in OA-induced inflammatory pain remains unclear. This review focused on lncRNAs involved in this type of pain. Similar to lncRNAs in the PNI model, various
lncRNAs may be differentially expressed and exert opposite effects in the pathogenesis of OA (Abbasifard et al., 2020; Xie et al., 2020). Li et al. (2018b) first found that the levels of lncRNA MEG3 increased in the articular tissue of an OA model after treatment with methylene blue, which improved pain sensitivity and reduced inflammatory pain in the OA model. MEG3 has been reported to play a protective role in chondrocytes against IL$1 \beta$-induced inflammation in an OA model (Huang et al., 2021). IL- $1 \beta$, IL-6, and TNF $\alpha$ levels were decreased in a methylene bluetreated OA model, and MEG3 siRNA increased the expression of IL- $1 \beta$, IL- 6 , and TNF- $\alpha$ reduced, following methylene blue treatment ( $\mathrm{Li}$ et al., 2018b), indicating that lncRNA MEG3 may alleviate $\mathrm{OA}$-induced pain by regulating inflammation. Subsequently, research was performed to investigate the effect of lncRNAs on the nervous system (Yang et al., 2021). Umbilical cord blood mesenchymal stem cells, which can release exosomes containing lncRNA H19, were intravenously, intracavitary, or intrathecally administered to an OA model, and all three types of administrations improved the pain sensitization of advanced OA. RT-qPCR analysis results suggested that serum IL-1 $\alpha$, IL-2, IL-6, and TNF- $\alpha$ levels were decreased by treatment with exo-lncRNA H19. In addition, activation of the ERK-signaling pathway in the spinal dorsal horn was inhibited by exo-lncRNA H19. These results indicate that lncRNAs may regulate the development of OA-induced pain via different mechanisms. Notably, different lncRNAs may play opposite roles in the inflammatory process of OA (Abbasifard et al., 2020; Xie et al., 2020); a similar phenomenon may appear in the development of OA-induced pain. The roles and mechanisms of different lncRNAs need to be validated.

\section{IncRNA AND CHRONIC CANCER-RELATED PAIN}

Chronic cancer-related pain, another type of chronic pain, similarly deteriorates the quality of life of patients. It can be caused by cancer itself (primary tumor or metastases) or by its treatment (surgery, chemotherapy, and radiotherapy) (Bennett et al., 2019). CCRP is characterized by symptoms of syndromes, including neuropathic and musculoskeletal pain (Treede et al., 2019). Many lncRNAs have been found to play a significant role in cancer, cancer metastasis, and cancer-associated treatment ( $\mathrm{Li}$ et al., 2016, 2021; Peng W.X. et al., 2017). Recently, accumulating 


\begin{tabular}{|c|c|c|c|c|}
\hline Up-regulated IncRNAs in BCP & \multicolumn{2}{|c|}{ Up-regulated IncRNAs in CIPN } & \multicolumn{2}{|c|}{ Down-regulated IncRNAs in CIPN } \\
\hline NONRATT007487.2, & Loc108353231 & Loc102553678 & Lxloc012126 & Lxloc001291 \\
\hline NONRATT 003582.2 & Loc024465 & Loc103690244 & Lxloc011574 & Lxloc017452 \\
\hline $\begin{array}{l}\text { NONRAI I026544.2 } \\
\text { NONRATT004661.2 }\end{array}$ & Loc103693147 & Lxloc017539 & Lxloc012123 & Lxloc018867 \\
\hline NONRATT008764.2 & Loc100910237 & Lxloc024464 & Lxloc011573 & Lxloc007757 \\
\hline \multirow{2}{*}{ Down-regulated IncRNAs in CIPN } & Loc108352467 & Lxloc001959 & Lxloc034631 & Lxloc035549 \\
\hline & Loc102555451 & Lxloc009597 & Lxloc017190 & Lxloc015298 \\
\hline MSTRG.12616.2 & Loc102547829 & Lxloc034027 & Lxloc029452 & Lxloc021976 \\
\hline MSTRG.13351.2 & Lxloc018745 & Lxloc000038 & Lxloc025643 & Lxloc015208 \\
\hline $\begin{array}{l}\text { MSTRG.16194.3 } \\
\text { MSTRG.16806.2 }\end{array}$ & Lxloc028716 & Lxloc034063 & Lxloc011438 & Lxloc012552 \\
\hline MSTRG.29385.15 & Lxloc022035 & Lxloc010634 & Lxloc014875 & Loc102550154 \\
\hline
\end{tabular}

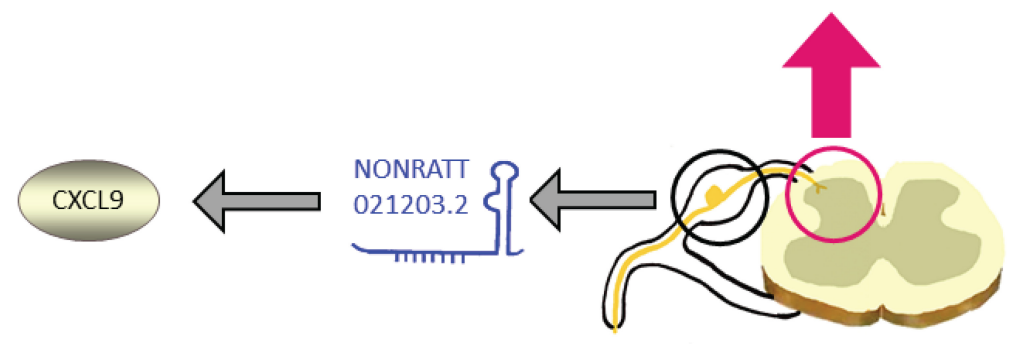

FIGURE 3 | Expression changes and mechanisms of long non-coding RNAs (IncRNAs) in CCRP: many IncRNAs are dysregulated by tumor metastasis and chemotherapy treatment. IncRNA NONRATT021203.2 can exert its effect on BCP by mediating CXCL9 release. BCP, bone cancer pain; CCRP, chronic cancer-related pain; CIPN, chemotherapy-induced peripheral neuropathy.

evidence has shown that lncRNAs are related to the development of CCRP (Figure 3).

\section{IncRNAs and Cancer-Induced Pain}

More than $50 \%$ of patients with cancer experience cancerinduced pain (CIP) (van den Beuken-van et al., 2016). Bone cancer pain (BCP) is the most common type of CIP and is mainly caused by metastatic tumors (Bennett et al., 2019). Many studies have focused on the role of lncRNAs in tumor metastasis (Weidle et al., 2017). This review focuses on the latest research findings on the effect of lncRNAs on CIP and identifies the roles of lncRNAs in metastatic tumor-induced pain. Transcriptome sequencing and RT-qPCR validated the change in the expression of 10 lncRNAs (five upregulated and five downregulated) in the ipsilateral lumbar spinal cord in a rat BCP model (Hou et al., 2020). Gene Ontology (GO) and Kyoto Encyclopedia of Genes and Genomes (KEGG) analysis of the dysregulated IncRNAs (NONRATT007487.2, NONRATT 003582.2, NONRATT026544.2, NONRATT004661.2, NONRATT008764.2, MSTRG.12616.2, MSTRG.13351.2, MSTRG.16194.3, MSTRG.16806.2, and MSTRG.29385.15) indicated that they were mainly involved in inflammatory and immunological responses. Inflammation in the nervous system has been reported to play an important role in BCP, and inhibiting this response could significantly attenuate BCP (Song et al., 2015; Chen S.P. et al., 2019), indicating the potential role of lncRNAs in the development of BCP. Another study further confirmed the link between lncRNAs and neuroinflammation in a BCP model (Sun et al., 2020). The researchers relieved hyperalgesia in $\mathrm{BCP}$ rats by treatment with IncRNA NONRATT021203.2 siRNA. In addition, the increased expression of C-X-C motif chemokine ligand 9 (CXCL9) in the DRG was inhibited by this siRNA. CXCL9 has been reported to play a pro-neuroinflammation role in the nervous system (Koper et al., 2018), and inhibiting CXCL9 expression could relieve hyperalgesia in BCP rats (Sun et al., 2020), indicating that NONRATT021203.2 could target CXCL9 and result in CIP in the BCP model. The findings from the two studies indicate that the IncRNA-neuroinflammation axis may be a potential target for the treatment of CIP.

\section{IncRNA and Chemotherapy-Induced Pain}

Chemotherapy-induced peripheral neuropathy is a neurotoxic adverse effect of many chemotherapeutic agents (Banach et al., 2017). Chronic pain is a major symptom of chemotherapyinduced peripheral neuropathy (CIPN) (Brewer et al., 2016). The mechanism underlying chemotherapy-induced pain remains unclear, and many medical treatments are usually insufficient for pain management (Sisignano et al., 2014). In a recent study, RNA sequencing (RNA-Seq) and bioinformatics analysis have been performed to explore lncRNA expression profiles in the spinal cord dorsal horn of rats treated with paclitaxel (Li et al., 2021), 
one of the most commonly used chemotherapeutic agents (Mody et al., 2016). These results suggest that dysregulated lncRNAs were primarily involved in the neurotrophin-signaling pathway. Neurotrophin signaling could result in the recruitment of signaling proteins (Scott-Solomon and Kuruvilla, 2018), which activate downstream intracellular-signaling pathways, including the ERK1/2 and NF- $\kappa$ B pathways. ERK1/2 and NF$\kappa \mathrm{B}$ signaling have been found to participate in paclitaxelinduced peripheral neuropathy (Wang G. J. et al., 2020; Zhao et al., 2020). These two signaling pathways have been identified downstream of lncRNAs (Peng H. et al., 2017; Zhao et al., 2018). This study indicated that lncRNAs may play an important role in the process of chemotherapy-induced pain by mediating the two signaling pathways; however, this needs to be further validated.

\section{CONCLUSION}

In recent years, an increasing number of studies have addressed the change in expression of lncRNAs in humans with chronic pain and preclinical pain models. The vital role of lncRNAs in chronic pain, including CNP, inflammatory pain, and CCRP, has been identified. These lncRNAs can participate in the development of chronic pain by interacting with miRNAs, regulating pro-inflammatory cytokine levels, and mediating signaling pathways. However, the regulatory effects of lncRNAs may be contradictory in different models or different issues.

\section{REFERENCES}

Abbasifard, M., Kamiab, Z., Bagheri-Hosseinabadi, Z., and Sadeghi, I. (2020). The role and function of long non-coding RNAs in osteoarthritis. Exp. Mol. Pathol. 114:104407. doi: 10.1016/j.yexmp.2020.104407

Baba, H., Petrenko, A. B., and Fujiwara, N. (2016). Clinically relevant concentration of pregabalin has no acute inhibitory effect on excitation of dorsal horn neurons under normal or neuropathic pain conditions: an intracellular calcium-imaging study in spinal cord slices from adult rats. Brain Res. 1648, 445-458. doi: 10.1016/j.brainres.2016.08.018

Banach, M., Juranek, J. K., and Zygulska, A. L. (2017). Chemotherapy-induced neuropathies-a growing problem for patients and health care providers. Brain Behav. 7:e00558. doi: 10.1002/brb3.558

Batista, P. J., and Chang, H. Y. (2013). Long noncoding RNAs: cellular address codes in development and disease. Cell 152, 1298-1307. doi: 10.1016/j.cell.2013. 02.012

Bennett, M. I., Kaasa, S., Barke, A., Korwisi, B., Rief, W., and Treede, R. D. (2019). The IASP classification of chronic pain for ICD-11: chronic cancer-related pain. Pain 160, 38-44. doi: 10.1097/j.pain.0000000000001363

Bernier, L. P., Ase, A. R., and Séguéla, P. (2018). P2X receptor channels in chronic pain pathways. Br. J. Pharmacol. 175, 2219-2230. doi: 10.1111/bph.13957

Bick, S. K. B., and Eskandar, E. N. (2017). Surgical treatment of trigeminal neuralgia. Neurosurg. Clin. N. Am. 28, 429-438.

Birklein, F., and Schlereth, T. (2015). Complex regional pain syndrome-significant progress in understanding. Pain 156(Suppl. 1), S94-S103. doi: 10.1097/01.j. pain. 0000460344.54470 .20

Bliss, T. V., Collingridge, G. L., Kaang, B. K., and Zhuo, M. (2016). Synaptic plasticity in the anterior cingulate cortex in acute and chronic pain. Nat. Rev. Neurosci. 17, 485-496. doi: 10.1038/nrn.2016.68

Bouhassira, D., Lantéri-Minet, M., Attal, N., Laurent, B., and Touboul, C. (2008). Prevalence of chronic pain with neuropathic characteristics in the general population. Pain 136, 380-387. doi: 10.1016/j.pain.2007.08.013
Some lncRNAs, such as XIST, are associated with sex-related differences. Thus, it is necessary to take these factors into account while exploring strategies for alleviating chronic pain. In addition, the same lncRNA could exert its effect on different types of chronic pain, indicating the existence of a similar mechanism underlying the development of different types of pain. Although lncRNA-based clinical agents for chronic pain have not been clearly determined, this preclinical exploration of the mechanism may provide novel and evidential insights for exploring effective strategies for lncRNA-based treatments for chronic pain. However, the clinical efficacy and risks involved in lncRNA therapy need to be systematically evaluated.

\section{AUTHOR CONTRIBUTIONS}

ZL wrote the first draft of the manuscript. XL and WJ accessed the data. QX and ZHL contributed to the manuscript revision. All authors contributed to the conception and design of the study, contributed to the article, and approved the submitted version.

\section{FUNDING}

This study was supported by grants from the National Natural Science Foundation of China (81901984) and the Shenzhen Science and Technology Innovation Committee (GJHZ20180926170402056).

Brewer, J. R., Morrison, G., Dolan, M. E., and Fleming, G. F. (2016). Chemotherapy-induced peripheral neuropathy: current status and progress. Gynecol. Oncol. 140, 176-183. doi: 10.1016/j.ygyno.2015. 11.011

Brown, K. K., Heitmeyer, S. A., Hookfin, E. B., Hsieh, L., Buchalova, M., Taiwo, Y. O., et al. (2008). P38 MAP kinase inhibitors as potential therapeutics for the treatment of joint degeneration and pain associated with osteoarthritis. J. Inflamm. 5:22. doi: 10.1186/1476-9255-5-22

Bu, H. L., Xia, Y. Z., Liu, P. M., Guo, H. M., Yuan, C., Fan, X. C., et al. (2019). The roles of chemokine CXCL13 in the development of bone cancer pain and the regulation of morphine analgesia in rats. Neuroscience 406, 62-72. doi: 10.1016/j.neuroscience.2019.02.025

Chen, M., Yang, Y., Zhang, W., Li, X., Wu, J., Zou, X., et al. (2020). Long noncoding RNA SNHG5 knockdown alleviates neuropathic pain by targeting the miR-1545p/CXCL13 axis. Neurochem. Res. 45, 1566-1575. doi: 10.1007/s11064-02003021-2

Chen, P., Wang, C., Lin, D., Li, B., Ye, S., Qu, J., et al. (2021). Identification of Slc6a19os and SOX11 as two novel essential genes in neuropathic pain using integrated bioinformatic analysis and experimental verification. Front. Neurosci. 15:627945. doi: 10.3389/fnins.2021.627945

Chen, S. P., Zhou, Y. Q., Wang, X. M., Sun, J., Cao, F., HaiSam, S., et al. (2019). Pharmacological inhibition of the NLRP3 inflammasome as a potential target for cancer-induced bone pain. Pharmacol. Res. 147:104339. doi: 10.1016/j.phrs. 2019.104339

Chen, W. K., Yu, X. H., Yang, W., Wang, C., He, W. S., Yan, Y. G., et al. (2017). lncRNAs: novel players in intervertebral disc degeneration and osteoarthritis. Cell Prolif. 50:e12313 doi: 10.1111/cpr.12313

Chen, Y., Li, G., and Huang, L. Y. (2012). P2X7 receptors in satellite glial cells mediate high functional expression of $\mathrm{P} 2 \mathrm{X} 3$ receptors in immature dorsal root ganglion neurons. Mol. Pain 8:9. doi: 10.1186/1744-8069-8-9

Chen, Z. L., Liu, J. Y., Wang, F., and Jing, X. (2019). Suppression of MALAT1 ameliorates chronic constriction injury-induced neuropathic pain in rats via 
modulating miR-206 and ZEB2. J Cell Physiol. Online ahead of print. doi: $10.1002 /$ jcp. 28213

Costa, F. A., and Moreira Neto, F. L. (2015). [Satellite glial cells in sensory ganglia: its role in pain]. Rev. Bras. Anestesiol. 65, 73-81. doi: 10.1016/j.bjane.2013. 07.013

de Mos, M., de Bruijn, A. G., Huygen, F. J., Dieleman, J. P., Stricker, B. H., and Sturkenboom, M. C. (2007). The incidence of complex regional pain syndrome: a population-based study. Pain 129, 12-20. doi: 10.1016/j.pain.2006.09.008

de Vos, C. C., Meier, K., Zaalberg, P. B., Nijhuis, H. J., Duyvendak, W., Vesper, J., et al. (2014). Spinal cord stimulation in patients with painful diabetic neuropathy: a multicentre randomized clinical trial. Pain 155, 2426-2431. doi: 10.1016/j.pain.2014.08.031

Dou, L., Lin, H., Wang, K., Zhu, G., Zou, X., Chang, E., et al. (2017). Long non-coding RNA CCAT1 modulates neuropathic pain progression through sponging miR-155. Oncotarget 8, 89949-89957. doi: 10.18632/oncotarget. 21192

Du, H., Liu, Z., Tan, X., Ma, Y., and Gong, Q. (2019). Identification of the genomewide expression patterns of long non-coding RNAs and mRNAs in mice with streptozotocin-induced diabetic neuropathic pain. Neuroscience 402, 90-103. doi: 10.1016/j.neuroscience.2018.12.040

Fillingim, R. B., King, C. D., Ribeiro-Dasilva, M. C., Rahim-Williams, B., et al. (2009). Sex, gender, and pain: a review of recent clinical and experimental findings. J. Pain 10, 447-485. doi: 10.1016/j.jpain.2008.12.001

Fullerton, E. F., Doyle, H. H., and Murphy, A. Z. (2018). Impact of sex on pain and opioid analgesia: a review. Curr. Opin. Behav. Sci. 23, 183-190. doi: 10.1016/j. cobeha.2018.08.001

Hamood, R., Hamood, H., Merhasin, I., and Keinan-Boker, L. (2018). Chronic pain and other symptoms among breast cancer survivors: prevalence, predictors, and effects on quality of life. Breast Cancer Res. Treat. 167, 157-169. doi: 10.1007/s10549-017-4485-0

Hansen, R. R., Vacca, V., Pitcher, T., Clark, A. K., and Malcangio, M. (2016). Role of extracellular calcitonin gene-related peptide in spinal cord mechanisms of cancer-induced bone pain. Pain 157, 666-676. doi: 10.1097/j.pain. 0000000000000416

Hou, X., Weng, Y., Guo, Q., Ding, Z., Wang, J., Dai, J., et al. (2020). Transcriptomic analysis of long noncoding RNAs and mRNAs expression profiles in the spinal cord of bone cancer pain rats. Mol. Brain 13:47. doi: 10.1186/s13041-02000589-2

Hu, J. Z., Rong, Z. J., Li, M., Li, P., Jiang, L. Y., Luo, Z. X., et al. (2019). Silencing of IncRNA PKIA-AS1 attenuates spinal nerve ligation-induced neuropathic pain through epigenetic downregulation of CDK6 Expression. Front. Cell Neurosci. 13:50. doi: $10.3389 /$ fncel.2019.00050

Huang, Y., Chen, D., Yan, Z., Zhan, J., Xue, X., Pan, X., et al. (2021). LncRNA MEG3 protects chondrocytes from IL-1 $\beta$-induced inflammation via regulating miR-95p/KLF4 Axis. Front. Physiol. 12:617654. doi: 10.3389/fphys.2021.617654

Jin, H., Du, X. J., Zhao, Y., and Xia, D. L. (2018). XIST/miR-544 axis induces neuropathic pain by activating STAT3 in a rat model. J. Cell. Physiol. 233, 5847-5855. doi: $10.1002 /$ jcp. 26376

Kong, C., Du, J., Bu, H., Huang, C., Xu, F., and Ren, H. (2020). LncRNA KCNA2AS regulates spinal astrocyte activation through STAT3 to affect postherpetic neuralgia. Mol. Med. 26:113. doi: 10.1186/s10020-020-00232-9

Koper, O. M., Kamińska, J., Sawicki, K., and Kemona, H. (2018). CXCL9, CXCL10, CXCL11, and their receptor (CXCR3) in neuroinflammation and neurodegeneration. Adv. Clin. Exp. Med. 27, 849-856. doi: 10.17219/acem/ 68846

Kuan, Y. H., and Shyu, B. C. (2016). Nociceptive transmission and modulation via P2X receptors in central pain syndrome. Mol. Brain 9:58. doi: 10.1186/s13041016-0240-4

Li, G., Jiang, H., Zheng, C., Zhu, G., Xu, Y., Sheng, X., et al. (2017). Long noncoding RNA MRAK009713 is a novel regulator of neuropathic pain in rats. Pain 158, 2042-2052.

Li, H., Fan, L., Zhang, Y., Cao, Y., and Liu, X. (2020). SNHG16 aggravates chronic constriction injury-induced neuropathic pain in rats via binding with miR124-3p and miR-141-3p to upregulate JAG1. Brain Res. Bull. 165, 228-237. doi: 10.1016/j.brainresbull.2020.09.025

Li, J., Meng, H., Bai, Y., and Wang, K. (2016). Regulation of lncRNA and its role in cancer metastasis. Oncol. Res. 23, 205-217. doi: 10.3727/ 096504016x14549667334007
Li, K., Jiao, Y., Ren, X., You, D., and Cao, R. (2020). Long noncoding RNA H19 induces neuropathic pain by upregulating cyclin-dependent Kinase 5-mediated phosphorylation of cAMP response element binding protein. J. Pain Res. 13, 2113-2124.

Li, X., Ren, W., Xiao, Z. Y., Wu, L. F., Wang, H., and Guo, P. Y. (2018a). GACAT3 promoted proliferation of osteoarthritis synoviocytes by IL-6/STAT3 signaling pathway. Eur. Rev. Med. Pharmacol. Sci. 22, 5114-5120. doi: 10.26355/eurrev_ 201808_15705

Li, X., Tang, C., Wang, J., Guo, P., Wang, C., Wang, Y., et al. (2018b). Methylene blue relieves the development of osteoarthritis by upregulating lncRNA MEG3. Exp. Ther. Med. 15, 3856-3864. doi: 10.3892/etm.2018.5918

Li, Y., Yin, C., Liu, B., Nie, H., Wang, J., Zeng, D., et al. (2021). Transcriptome profiling of long noncoding RNAs and mRNAs in spinal cord of a rat model of paclitaxel-induced peripheral neuropathy identifies potential mechanisms mediating neuroinflammation and pain. J. Neuroinflamm. 18:48. doi: 10.1186/ s12974-021-02098-y

Li, Z., Li, A., Yan, L., Yang, T., Xu, W., and Fan, P. (2020). Downregulation of long noncoding RNA DLEU1 attenuates hypersensitivity in chronic constriction injury-induced neuropathic pain in rats by targeting miR-133a-3p/SRPK1 axis. Mol. Med. 26:104. doi: 10.1186/s10020-020-00235-6

Liang, R., Yong, S., Huang, X., Kong, H., Hu, G., and Fan, Y. (2016). Aquaporin4 mediates the suppressive effect of lipopolysaccharide on hippocampal neurogenesis. Neuroimmunomodulation 23, 309-317. doi: 10.1159/000467141

Lin, X., Wang, M., Zhang, J., and Xu, R. (2014). p38 MAPK: a potential target of chronic pain. Curr. Med. Chem. 21, 4405-4418.

Liu, C., Li, C., Deng, Z., Du, E., and Xu, C. (2018). Long non-coding RNA BC168687 is involved in TRPV1-mediated diabetic neuropathic pain in rats. Neuroscience 374, 214-222. doi: 10.1016/j.neuroscience.2018.01.049

Liu, C., Tao, J., Wu, H., Yang, Y., Chen, Q., Deng, Z., et al. (2017). Effects of LncRNA BC168687 siRNA on diabetic neuropathic pain mediated by $\mathrm{P} 2 \mathrm{X}(7)$ receptor on SGCs in DRG of rats. Biomed. Res. Int. 2017:7831251. doi: 10.1155/2017/ 7831251

Liu, S., Zou, L., Xie, J., Xie, W., Wen, S., Xie, Q., et al. (2016). LncRNA NONRATT021972 siRNA regulates neuropathic pain behaviors in type 2 diabetic rats through the $\mathrm{P} 2 \mathrm{X} 7$ receptor in dorsal root ganglia. Mol. Brain 9:44. doi: 10.1186/s13041-016-0226-2

Liu, Y., Feng, L., Ren, S., Zhang, Y., and Xue, J. (2020). Inhibition of IncRNA DILC attenuates neuropathic pain via the SOCS3/JAK2/STAT3 pathway. Biosci. Rep. 40:BSR20194486. doi: 10.1042/BSR20194486

Liu, Y., Sun, H., and Sun, Y. (2021). LncRNA p21, downregulating miR$181 \mathrm{~b}$, aggravates neuropathic pain by upregulating Tnfaip1 and inhibit the AKT/CREB axis. Brain Res. Bull. 171, 150-161. doi: 10.1016/j.brainresbull. 2021.03.005

Ma, X., Wang, H., Song, T., Wang, W., and Zhang, Z. (2020). IncRNA MALAT1 contributes to neuropathic pain development through regulating miR-129$5 \mathrm{p} / \mathrm{HMGB} 1$ axis in a rat model of chronic constriction injury. Int. J. Neurosci. 130, 1215-1224. doi: 10.1080/00207454.2020.1731508

Mao, P., Li, C. R., Zhang, S. Z., Zhang, Y., Liu, B. T., and Fan, B. F. (2018). Transcriptomic differential lncRNA expression is involved in neuropathic pain in rat dorsal root ganglion after spared sciatic nerve injury. Braz. J. Med. Biol. Res. 51:e7113. doi: 10.1590/1414-431X20187113

Meng, C., Yang, X., Liu, Y., Zhou, Y., Rui, J., Li, S., et al. (2019). Decreased expression of lncRNA Malatl in rat spinal cord contributes to neuropathic pain by increasing neuron excitability after brachial plexus avulsion. J. Pain Res. 12, 1297-1310. doi: 10.2147/JPR.S195117

Mody, M. D., Gill, H. S., and Saba, N. F. (2016). The evolving and future role of taxanes in squamous cell carcinomas of the head and neck: a review. JAMA Otolaryngol. Head Neck Surg. 142, 898-905. doi: 10.1001/jamaoto.2016.1238

Ong, W. Y., Stohler, C. S., and Herr, D. R. (2019). Role of the prefrontal cortex in pain processing. Mol. Neurobiol. 56, 1137-1166. doi: 10.1007/s12035-018$1130-9$

Pan, X., Shen, C., Huang, Y., Wang, L., and Xia, Z. (2020). Loss of SNHG4 attenuated spinal nerve ligation-triggered neuropathic pain through sponging miR-423-5p. Mediators Inflamm. 2020:2094948.

Pang, H., Ren, Y., Li, H., Chen, C., and Zheng, X. (2020). LncRNAs linc00311 and AK141205 are identified as new regulators in STAT3-mediated neuropathic pain in bCCI rats. Eur. J. Pharmacol. 868:172880. doi: 10.1016/j.ejphar.2019. 172880 
Peng, C., Zhang, C., Su, Z., and Lin, D. (2019). DGCR5 attenuates neuropathic pain through sponging miR-330-3p and regulating PDCD4 in CCI rat models. J. Cell. Physiol. 234, 7292-7300. doi: 10.1002/jcp.27487

Peng, H., Zou, L., Xie, J., Wu, H., Wu, B., Zhu, G., et al. (2017). IncRNA NONRATT021972 siRNA decreases diabetic neuropathic pain mediated by the P2X(3) receptor in dorsal root ganglia. Mol. Neurobiol. 54, 511-523. doi: 10.1007/s12035-015-9632-1

Peng, W. X., Koirala, P., and Mo, Y. Y. (2017). LncRNA-mediated regulation of cell signaling in cancer. Oncogene 36, 5661-5667. doi: 10.1038/onc.2017.184

Puchałowicz, K., Baranowska-Bosiacka, I., Dziedziejko, V., and Chlubek, D. (2015). Purinergic signaling and the functioning of the nervous system cells. Cell Mol. Biol. Lett. 20, 867-918.

Qian, Y., Wang, Q., Jiao, J., Wang, G., Gu, Z., Huang, D., et al. (2019). Intrathecal injection of dexmedetomidine ameliorates chronic neuropathic pain via the modulation of MPK3/ERK1/2 in a mouse model of chronic neuropathic pain. Neurol. Res. 41, 1059-1068. doi: 10.1080/01616412.2019.1672391

Ren, X., Yang, R., Li, L., Xu, X., and Liang, S. (2020). Long non coding RNAs involved in MAPK pathway mechanism mediates diabetic neuropathic pain. Cell Biol. Int. 44, 2372-2379. doi: 10.1002/cbin.11457

Rondón, L. J., Farges, M. C., Davin, N., Sion, B., Privat, A. M., Vasson, M. P., et al. (2018). L-Arginine supplementation prevents allodynia and hyperalgesia in painful diabetic neuropathic rats by normalizing plasma nitric oxide concentration and increasing plasma agmatine concentration. Eur. J. Nutr. 57, 2353-2363. doi: 10.1007/s00394-017-1508-x

Scholz, J., Finnerup, N. B., Attal, N., Aziz, Q., Baron, R., Bennett, M. I., et al. (2019). The IASP classification of chronic pain for ICD-11: chronic neuropathic pain. Pain 160, 53-59.

Schreiber, A. K., Nones, C. F., Reis, R. C., Chichorro, J. G., and Cunha, J. M. (2015). Diabetic neuropathic pain: physiopathology and treatment. World J. Diabetes 6, 432-444.

Schwartzman, R. J., Erwin, K. L., and Alexander, G. M. (2009). The natural history of complex regional pain syndrome. Clin. J. Pain 25, 273-280.

Scott-Solomon, E., and Kuruvilla, R. (2018). Mechanisms of neurotrophin trafficking via Trk receptors. Mol. Cell. Neurosci. 91, 25-33. doi: 10.1016/j.mcn. 2018.03.013

Seino, D., Tokunaga, A., Tachibana, T., Yoshiya, S., Dai, Y., Obata, K., et al. (2006). The role of ERK signaling and the P2X receptor on mechanical pain evoked by movement of inflamed knee joint. Pain 123, 193-203. doi: 10.1016/j.pain.2006. 02.032

Sellam, J., and Berenbaum, F. (2010). The role of synovitis in pathophysiology and clinical symptoms of osteoarthritis. Nat. Rev. Rheumatol. 6, 625-635. doi: 10.1038/nrrheum.2010.159

Shen, F., Zheng, H., Zhou, L., Li, W., Zhang, Y., and Xu, X. (2019). LINC00657 expedites neuropathic pain development by modulating miR-136/ZEB1 axis in a rat model. J. Cell. Biochem. 120, 1000-1010. doi: 10.1002/jcb.27466

Shenoda, B. B., Tian, Y., Alexander, G. M., Aradillas-Lopez, E., Schwartzman, R. J., and Ajit, S. K. (2018). miR-34a-mediated regulation of XIST in female cells under inflammation. J. Pain Res. 11, 935-945. doi: 10.2147/JPR.S1 59458

Sisignano, M., Baron, R., Scholich, K., and Geisslinger, G. (2014). Mechanismbased treatment for chemotherapy-induced peripheral neuropathic pain. Nat. Rev. Neurol. 10, 694-707.

Song, H., Han, Y., Pan, C., Deng, X., Dai, W., Hu, L., et al. (2015). Activation of adenosine monophosphate-activated protein kinase suppresses neuroinflammation and ameliorates bone cancer pain: involvement of inhibition on mitogen-activated protein kinase. Anesthesiology 123, 1170-1185. doi: 10.1097/ALN.0000000000000856

Sun, H., Peng, G., Ning, X., Wang, J., Yang, H., and Deng, J. (2019). Emerging roles of long noncoding RNA in chondrogenesis, osteogenesis, and osteoarthritis. Am. J. Transl. Res. 11, 16-30.

Sun, R. M., Wei, J., Wang, S. S., Xu, G. Y., and Jiang, G. Q. (2020). Upregulation of IncRNA-NONRATT021203.2 in the dorsal root ganglion contributes to cancerinduced pain via CXCL9 in rats. Biochem. Biophys. Res. Commun. 524, 983-989. doi: 10.1016/j.bbrc.2020.01.163

Sun, W., Ma, M., Yu, H., and Yu, H. (2018). Inhibition of IncRNA X inactivatespecific transcript ameliorates inflammatory pain by suppressing satellite glial cell activation and inflammation by acting as a sponge of miR-146a to inhibit $\mathrm{Na}$ (v) 1.7. J. Cell Biochem. 119, 9888-9898. doi: 10.1002/jcb.27310
Tang, W., Zhang, L., and Li, Z. (2021). Long noncoding RNA LOC100911498 is a novel regulator of neuropathic pain in rats. Brain Behav. 11:e01966. doi: $10.1002 / b r b 3.1966$

Thippeswamy, T., McKay, J. S., Morris, R., Quinn, J., Wong, L. F., and Murphy, D. (2005). Glial-mediated neuroprotection: evidence for the protective role of the NO-cGMP pathway via neuron-glial communication in the peripheral nervous system. Glia 49, 197-210. doi: 10.1002/glia.20105

Tian, Y., Sun, L., and Qi, T. (2020). Long noncoding RNA GAS5 ameliorates chronic constriction injury induced neuropathic pain in rats by modulation of the miR-452-5p/CELF2 axis. Can. J. Physiol. Pharmacol. 98, 870-877. doi: 10.1139/cjpp-2020-0036

Treede, R. D., Rief, W., Barke, A., Aziz, Q., Bennett, M. I., Benoliel, R., et al. (2019). Chronic pain as a symptom or a disease: the IASP classification of chronic pain for the International Classification of Diseases (ICD-11). Pain 160, 19-27.

Tsuda, M., Masuda, T., Kitano, J., Shimoyama, H., Tozaki-Saitoh, H., and Inoue, K. (2009). IFN-gamma receptor signaling mediates spinal microglia activation driving neuropathic pain. Proc. Natl. Acad. Sci. U.S.A. 106, 8032-8037. doi: 10.1073/pnas.0810420106

Ulitsky, I., and Bartel, D. P. (2013). lincRNAs: genomics, evolution, and mechanisms. Cell 154, 26-46. doi: 10.1016/j.cell.2013.06.020

Vacca, M., Della Ragione, F., Scalabrì, F., and D’Esposito, M. (2016). X inactivation and reactivation in X-linked diseases. Semin. Cell Dev. Biol. 56, 78-87. doi: 10.1016/j.semcdb.2016.03.009

van den Beuken-van, Everdingen, M. H., Hochstenbach, L. M., Joosten, E. A., Tjan-Heijnen, V. C., and Janssen, D. J. (2016). Update on prevalence of pain in patients with cancer: systematic review and meta-analysis. J. Pain Symptom Manage. 51, 1070-1090.e1079.

van Hecke, O., Austin, S. K., Khan, R. A., Smith, B. H., and Torrance, N. (2014). Neuropathic pain in the general population: a systematic review of epidemiological studies. Pain 155, 654-662. doi: 10.1016/j.pain.2013.11.013

Wang, D., Couture, R., and Hong, Y. (2014). Activated microglia in the spinal cord underlies diabetic neuropathic pain. Eur. J. Pharmacol. 728, 59-66.

Wang, G. J., Zhang, X., Huang, L. D., and Xiao, Y. (2020). Involvement of the sodium channel Nav1.7 in paclitaxel-induced peripheral neuropathy through ERK1/2 signaling in rats. Curr. Neurovasc. Res. 17, 267-274. doi: 10.2174/ 1567202617666200514113441

Wang, K. C., and Chang, H. Y. (2011). Molecular mechanisms of long noncoding RNAs. Mol. Cell. 43, 904-914. doi: 10.1016/j.molcel.2011.08.018

Wang, L., Zhu, K., Yang, B., and Cai, Y. (2020). Knockdown of Linc00052 alleviated spinal nerve ligation-triggered neuropathic pain through regulating miR-448 and JAK1. J. Cell. Physiol. 235, 6528-6535. doi: 10.1002/jcp.29465

Wang, S., Xu, H., Zou, L., Xie, J., Wu, H., Wu, B., et al. (2016). LncRNA uc.48+ is involved in diabetic neuropathic pain mediated by the P2X3 receptor in the dorsal root ganglia. Purinergic Signal. 12, 139-148. doi: 10.1007/s11302-0159488-x

Wang, W., Min, L., Qiu, X., Wu, X., Liu, C., Ma, J., et al. (2021). Biological function of long non-coding RNA (LncRNA) Xist. Front. Cell Dev. Biol. 9:645647.

Wei, M., Li, L., Zhang, Y., Zhang, Z. J., Liu, H. L., and Bao, H. G. (2018). LncRNA $\mathrm{X}$ inactive specific transcript contributes to neuropathic pain development by sponging miR-154-5p via inducing toll-like receptor 5 in CCI rat models. J. Cell Biochem. Online ahead of print. doi: 10.1002/jcb.27088

Weidle, U. H., Birzele, F., Kollmorgen, G., and Rüger, R. (2017). Long non-coding RNAs and their role in metastasis. Cancer Genomics Proteom. 14, 143-160.

Wen, J., Yang, Y., Wu, S., Wei, G., Jia, S., Hannaford, S., et al. (2020). Long noncoding RNA H19 in the injured dorsal root ganglion contributes to peripheral nerve injury-induced pain hypersensitivity. Transl. Perioper. Pain Med. 7, 176-184.

Wen, Y., Fan, X., Bu, H., Ma, L., Kong, C., Huang, C., et al. (2021). Downregulation of IncRNA FIRRE relieved the neuropathic pain of female mice by suppressing HMGB1 expression. Mol. Cell. Biochem. 476, 841-852. doi: 10.1007/s11010020-03949-7

Wu, J., Wang, C., and Ding, H. (2020). LncRNA MALAT1 promotes neuropathic pain progression through the miR-154-5p/AQP9 axis in CCI rat models. Mol. Med. Rep. 21, 291-303. doi: 10.3892/mmr.2019.10829

Wu, Y., Shen, Z., Xu, H., Zhang, K., Guo, M., Wang, F., et al. (2021). BDNF Participates in chronic constriction injury-induced neuropathic pain via transcriptionally activating P2X(7) in primary sensory neurons. Mol. Neurobiol. 58, 4226-4236. doi: 10.1007/s12035-021-02410-0 
Xia, L. P., Luo, H., Ma, Q., Xie, Y. K., Li, W., Hu, H., et al. (2021). GPR151 in nociceptors modulates neuropathic pain via regulating $\mathrm{P} 2 \mathrm{X} 3$ function and microglial activation. Brain doi: 10.1093/brain/awab245 [Epub ahead of print].

Xia, L. X., Ke, C., and Lu, J. M. (2018). NEAT1 contributes to neuropathic pain development through targeting miR-381/HMGB1 axis in CCI rat models. J. Cell. Physiol. 233, 7103-7111. doi: 10.1002/jcp.26526

Xian, S., Ding, R., Li, M., and Chen, F. (2021). LncRNA NEAT1/miR-128-3p/AQP4 axis regulating spinal cord injury-induced neuropathic pain progression. J. Neuroimmunol. 351:577457. doi: 10.1016/j.jneuroim.2020.577457

Xiao, Y., Yan, X., Yang, Y., and Ma, X. (2019). Downregulation of long noncoding RNA HOTAIRM1 variant 1 contributes to osteoarthritis via regulating miR-125b/BMPR2 axis and activating JNK/MAPK/ERK pathway. Biomed. Pharmacother. 109, 1569-1577. doi: 10.1016/j.biopha.2018.10.181

Xie, F., Liu, Y. L., Chen, X. Y., Li, Q., Zhong, J., Dai, B. Y., et al. (2020). Role of MicroRNA, LncRNA, and exosomes in the progression of osteoarthritis: a review of recent literature. Orthop. Surg. 12, 708-716. doi: 10.1111/os.12690

Xiong, W., Huang, L., Shen, Y., Guan, S., He, L., Tong, Z., et al. (2017). Effects of lncRNA uc.48+ siRNA on the release of CGRP in the spinal cords of rats with diabetic neuropathic pain. Int. J. Clin. Exp. Pathol. 10, 9960-9969.

Xiong, W., Tan, M., Tong, Z., Yin, C., He, L., Liu, L., et al. (2019). Effects of long non-coding RNA uc.48+ on pain transmission in trigeminal neuralgia. Brain Res. Bull. 147, 92-100. doi: 10.1016/j.brainresbull.2019.02.009

Xu, M., Yan, Y., Zhu, M., Wang, Z., Zhang, X., and Zhang, D. (2020). Effects of long non-coding RNA Gm14461 on pain transmission in trigeminal neuralgia. J. Inflamm. 17:1. doi: 10.1186/s12950-019-0231-1

Yan, X. T., Lu, J. M., Wang, Y., Cheng, X. L., He, X. H., Zheng, W. Z., et al. (2018). XIST accelerates neuropathic pain progression through regulation of miR-150 and ZEB1 in CCI rat models. J. Cell. Physiol. 233, 6098-6106. doi: $10.1002 /$ jcp. 26453

Yang, Q., Yao, Y., Zhao, D., Zou, H., Lai, C., Xiang, G., et al. (2021). LncRNA H19 secreted by umbilical cord blood mesenchymal stem cells through microRNA$29 \mathrm{a}-3 \mathrm{p} / \mathrm{FOS}$ axis for central sensitization of pain in advanced osteoarthritis. Am. J. Transl. Res. 13, 1245-1256.

Yu, W., Zhao, G. Q., Cao, R. J., Zhu, Z. H., and Li, K. (2017). LncRNA NONRATT021972 was associated with neuropathic pain scoring in patients with type 2 diabetes. Behav. Neurol. 2017:2941297. doi: 10.1155/2017/2941297

Zhang, B. Y., Zhang, Y. L., Sun, Q., Zhang, P. A., Wang, X. X., Xu, G. Y., et al. (2020). Alpha-lipoic acid downregulates TRPV1 receptor via NF- $\kappa$ B and attenuates neuropathic pain in rats with diabetes. CNS Neurosci. Ther. 26, 762-772. doi: $10.1111 /$ cns. 13303

Zhang, C., Peng, Y., Wang, Y., Xu, H., and Zhou, X. (2020). Transcribed ultraconserved noncoding RNA uc. 153 is a new player in neuropathic pain. Pain 161, 1744-1754. doi: 10.1097/j.pain.0000000000001868

Zhang, D., Mou, J. Y., Wang, F., Liu, J., and Hu, X. (2019). CRNDE enhances neuropathic pain via modulating miR-136/IL6R axis in CCI rat models. J. Cell. Physiol. 234, 22234-22241. doi: 10.1002/jcp.28790

Zhang, J. Y., Lv, D. B., Su, Y. N., Wang, X. L., Sheng, W. C., Yang, G., et al. (2020). LncRNA SNHG1 attenuates neuropathic pain following spinal cord injury by regulating CDK4 level. Eur. Rev. Med. Pharmacol. Sci. 24, 12034-12040. doi: 10.26355/eurrev_202012_23992
Zhang, L., Feng, H., Jin, Y., Zhan, Y., Han, Q., Zhao, X., et al. (2021). Long Non-coding RNA LINC01119 promotes neuropathic pain by stabilizing BDNF transcript. Front. Mol. Neurosci. 14:673669. doi: 10.3389/fnmol.2021.673669

Zhang, P., Sun, H., and Ji, Z. (2021). Downregulating lncRNA PVT1 relieves astrocyte overactivation induced neuropathic pain through targeting miR186-5p/CXCL13/CXCR5 axis. Neurochem. Res. 46, 1457-1469. doi: 10.1007/ s11064-021-03287-0

Zhang, Q., Zhou, L., Xie, H., Zhang, H., and Gao, X. (2021). HAGLR aggravates neuropathic pain and promotes inflammatory response and apoptosis of lipopolysaccharide-treated SH-SY5Y cells by sequestering miR-182-5p from ATAT1 and activating NLRP3 inflammasome. Neurochem. Int. 145:105001. doi: 10.1016/j.neuint.2021.105001

Zhang, Z., Sun, X., Zhao, G., Ma, Y., and Zeng, G. (2021). LncRNA embryonic stem cells expressed 1 (Lncencl) is identified as a novel regulator in neuropathic pain by interacting with EZH2 and downregulating the expression of Bail in mouse microglia. Exp. Cell Res. 399:112435. doi: 10.1016/j.yexcr.2020.112435

Zhao, J., Yang, L., Huang, L., and Li, Z. (2021). Screening of disease-related biomarkers related to neuropathic pain (NP) after spinal cord injury (SCI). Hum. Genom. 15:5. doi: 10.1186/s40246-021-00303-w

Zhao, X., Shen, L., Xu, L., Wang, Z., Ma, C., and Huang, Y. (2016). Inhibition of CaMKIV relieves streptozotocin-induced diabetic neuropathic pain through regulation of HMGB1. BMC Anesthesiol. 16:27. doi: 10.1186/s12871-0160191-4

Zhao, X., Tang, Z., Zhang, H., Atianjoh, F. E., Zhao, J. Y., Liang, L., et al. (2013). A long noncoding RNA contributes to neuropathic pain by silencing Kcna2 in primary afferent neurons. Nat. Neurosci. 16, 1024-1031. doi: 10.1038/nn.3438

Zhao, Y. X., Yao, M. J., Liu, Q., Xin, J. J., Gao, J. H., and Yu, X. C. (2020). Electroacupuncture treatment attenuates paclitaxel-induced neuropathic pain in rats via inhibiting spinal glia and the TLR4/NF-кВ pathway. J. Pain Res. 13, 239-250. doi: 10.2147/JPR.S241101

Zhao, Y., Li, S., Xia, N., Shi, Y., and Zhao, C. M. (2018). Effects of XIST/miR-137 axis on neuropathic pain by targeting TNFAIP1 in a rat model. J. Cell. Physiol. 233, 4307-4316. doi: 10.1002/jcp.26254

Conflict of Interest: The authors declare that the research was conducted in the absence of any commercial or financial relationships that could be construed as a potential conflict of interest.

Publisher's Note: All claims expressed in this article are solely those of the authors and do not necessarily represent those of their affiliated organizations, or those of the publisher, the editors and the reviewers. Any product that may be evaluated in this article, or claim that may be made by its manufacturer, is not guaranteed or endorsed by the publisher.

Copyright (c) $2021 \mathrm{Li}$, Li, Jian, Xue and Liu. This is an open-access article distributed under the terms of the Creative Commons Attribution License (CC BY). The use, distribution or reproduction in other forums is permitted, provided the original author(s) and the copyright owner(s) are credited and that the original publication in this journal is cited, in accordance with accepted academic practice. No use, distribution or reproduction is permitted which does not comply with these terms. 